\title{
Elementary school staff knowledge about management of traumatic dental injuries
}

This article was published in the following Dove Press journal:

Clinical, Cosmetic and Investigational Dentistry

\author{
Fares S Al-Sehaibany' \\ Danah Z Almubarak ${ }^{2}$ \\ Reem A Alajlan² \\ Mohammad A Aldosari' \\ Nasser D Alqahtani' \\ Nassr S Almaflehi ${ }^{3}$ \\ Sahar F AlBarakati' \\ 'Department of Pediatric Dentistry \\ and Orthodontics, College of \\ Dentistry, King Saud University, \\ Riyadh, Saudi Arabia; ${ }^{2}$ Dental Intern, \\ College of Dentistry, King Saud \\ University, Riyadh, Saudi Arabia; \\ ${ }^{3}$ Department of Periodontics and \\ Community Dentistry, College of \\ Dentistry, King Saud University, \\ Riyadh, Saudi Arabia
}

\begin{abstract}
Aim: This study investigated the knowledge of elementary school staff regarding the management of traumatic dental injuries (TDIs) in children.

Methods: The present cross-sectional study analyzed data collected between September 2016 and April 2017. The sample consisted of 2,027 elementary school staff members in Riyadh, Saudi Arabia. A stratified cluster random sampling technique was used to select the required sample. Those who agreed to participate in the study completed a 4-part self-administered questionnaire comprising questions regarding demographic data, knowledge on management of tooth fracture, and avulsion using photographs of TDI cases.

Results: The majority of the school staff showed inadequate basic knowledge regarding the importance of saving the broken piece of the tooth and identifying the tooth involved in the trauma ( $67 \%$ and $66.3 \%$, respectively), $P<0.05$. However, they had a significantly high number of correct responses regarding the immediate management of TDIs for the 2 case scenarios presented in the questionnaire $(P<0.05)$, and the majority $(41 \%)$ reported normal saline as a suitable storage medium $(P<0.01)$.
\end{abstract}

Conclusion: This study revealed a lack of knowledge in certain aspects of TDIs among elementary school staff.

Keywords: school staff, knowledge, traumatic dental injuries

\section{Introduction}

Traumatic dental injuries (TDIs) in school-age children and adolescents have been recognized as a serious issue globally because of their alarmingly high frequency and the nature of treatment, which is complex, expensive, and sometimes lasts several years beyond the incident. ${ }^{1,2}$

In addition to oral and environmental factors, various human behavioral factors, such as risk-taking recreational activities, active participation in sports without taking precautions, or emotionally stressful situations, increase the risk of TDIs in children. . $^{3,4}$

First-aid provided by those present at the site of the traumatic incident, which includes school staff, is crucial, and immediate appropriate management plays an important role in the prognosis of injured teeth. ${ }^{5,6}$ However, several studies conducted in different countries have reported that teachers, sports coaches, and school personnel, in general, lack adequate knowledge for managing dental trauma cases. ${ }^{7-10}$ A similar lack of knowledge among school teachers has been reported in different Middle Eastern regions. ${ }^{11,12}$ As a positive solution, specific prevention strategies emphasizing management of dental trauma can be applied in school environments. ${ }^{13}$
Correspondence: Fares S Al-Sehaibany Department of Pediatric Dentistry and Orthodontics, College of Dentistry, King Saud University, PO Box 60169, Riyadh

I I545, Saudi Arabia

Tel +966 II 46774 II

Email falsehaibany@ksu.edu.sa 
Duration of work experience and previous training in handling TDIs are some of the factors that influence school staff knowledge and decision making in the event of a traumatic incident. ${ }^{14}$ To optimize the inclusion of TDIs topics in school staff curricular training and to emphasize instructive education in a continuous manner, the present study was undertaken to investigate the knowledge of elementary school staff regarding the management of TDIs in children.

\section{Materials and methods}

The present cross-sectional study analyzed data collected between September 2016 and April 2017 from 2,027 elementary school staff members in Riyadh, Saudi Arabia. The study protocol and consent form were approved by the Research and Ethical Committee of Human Studies at the College of Dentistry Research Center (FR 0398) of King Saud University, Riyadh, Saudi Arabia. A stratified cluster random sampling technique was used to select the sample. The city of Riyadh was divided into 5 regions. The sample was recruited from 3 elementary schools in each region that were randomly selected from a list of elementary schools obtained from the Ministry of Education, Saudi Arabia. The school staff received letters explaining the nature of the study and an informed consent form. Those who agreed to participate in the study provided written informed consent and received a 4-part self-administered questionnaire with questions regarding demographic data, knowledge on management of tooth fracture, and avulsion using photographs of TDI cases. Prior to conducting the study, permission was obtained from the author and the publisher of the textbook Essentials of Traumatic Injuries to the Teeth: A Step-by-Step Treatment Guide to utilize the TDI photos in the present study. ${ }^{15}$

The questionnaire was pretested in a pilot survey of 40 randomly selected school staff who were not included in the main study. The staff were asked to complete the questionnaire on 2 different occasions separated by 1 week. The questionnaire was found to be suitable for use with the study population because there was high concurrence between the answers to the questions on both occasions. Cronbach's $\alpha$ was used to determine the reliability of the questionnaire, which was found to be 0.86 . The data obtained from the questionnaires were manually entered into the Statistical Package for the Social Sciences software package (SPSS version 20, IBM Corporation, Armonk, NY, USA) and analyzed using a significance level set at $P<0.05$. The Chi-square test was used to identify differences in responses for different variables.

\section{Results}

A total of 2,450 questionnaires were distributed to school staff members, 2,027 of which were completed and returned giving a response rate of $82.7 \%$. The mean age of the participants was $30 \pm 7.21$ years. The demographic characteristics of the respondents in terms of personal and professional information are presented in Table 1. The majority of the participants were from government schools (72.6\%) and had a bachelor's degree $(82.9 \%)$. More than half of the study population comprised school teachers (54.2\%).

The responses to part II of the questionnaire, which included questions related to knowledge of TDIs, are presented in Table 2 . Nearly two-thirds (65.3\%) of the school staff had witnessed TDIs in the past. The majority of the respondents had not attended any training courses related to TDIs (81.9\%), nor had they received any information regarding TDIs in the past (61.4\%). Among those who had received information regarding TDIs in the past, the majority reported that their source of information was a dentist (35.7\%).

Part III of the questionnaire presented 2 case scenarios with clinical photographs, as described in Table 3. The first case scenario was an 11-year-old child who had fallen and broken a maxillary permanent central incisor (Figure 1). The second case scenario was a 9-year-old child who had

Table I Responses to part I: participant personal and professional information

\begin{tabular}{ll}
\hline Variables & Total N=2,027, $\mathbf{n}(\%)$ \\
\hline Gender & $955(47.1)$ \\
Male & $1,072(52.9)$ \\
Female & $997(49.2)$ \\
Age (in years) & $608(30.0)$ \\
$<25$ & $304(15.0)$ \\
$25-35$ & $118(5.8)$ \\
$>35-45$ & \\
$>45$ & $1,680(82.9)$ \\
Level of education & $286(14.1)$ \\
Bachelor's degree & $61(3.0)$ \\
Diploma & \\
Master's degree or higher & $1,098(54.2)$ \\
Position at school & $426(21.0)$ \\
Teacher & $341(16.8)$ \\
Supervisor & $101(5.0)$ \\
Administrator & $61(3.0)$ \\
Nurse & $1,472(72.6)$ \\
Others & $555(27.4)$ \\
School type & \\
Government & Private
\end{tabular}

Note: Descriptive statistics showing number and percentage. 
fallen and knocked out a maxillary permanent central incisor (Figure 2). For the management of the first case scenario, the majority $(86.3 \% ; P<0.01)$ of the school staff responded

Table 2 Responses to part II: participant knowledge regarding TDls

\begin{tabular}{ll}
\hline Questions & $\begin{array}{l}\text { Total } \mathbf{N}=\mathbf{2 , 0 2 7} \\
\mathbf{n}(\%)\end{array}$ \\
\hline $\begin{array}{l}\text { QI. Have you witnessed TDIs in the past? } \\
\text { Yes }\end{array}$ & $\mathrm{I}, 324(65.3)$ \\
No & $703(34.7)$ \\
Q2. Have you ever attended a TDIs training & \\
course? & \\
Yes & $367(18.1)$ \\
No & $1,660(81.9)$ \\
Q3. Have you received information about TDIs in & \\
the past? & \\
Yes & $783(38.6)$ \\
No & $1,244(61.4)$ \\
Q4. If yes, what was the source of the information? & \\
Dentist & $724(35.7)$ \\
Physician & $264(13.0)$ \\
Friend & $243(12.0)$ \\
Internet/social network & $45 \mathrm{I}(22.3)$ \\
Other & $345(17.0)$ \\
\hline
\end{tabular}

Note: Descriptive statistics showing number and percentage. Abbreviation: TDIs, traumatic dental injuries. that they would send the child to the dentist immediately. However, the majority of the participants $(48.5 \% ; P<0.05)$ believed that it was not necessary to save the broken piece of tooth.

For the management of the second case scenario, the majority of the school staff $(41.9 \% ; P<0.05)$ indicated that they would take immediate action to save the knocked-out tooth in storage medium and send the child to the dentist immediately. The medium most frequently selected as suitable for storing the knocked-out tooth was normal saline (41\%; $P<0.01)$. However, more than one-third $(41.3 \%$; $P<0.05)$ of the participants selected the response stating that the knocked-out tooth was most likely to be a baby tooth.

The last part of the questionnaire assessed participant self-interest in managing TDIs and learning more about them, as presented in Table 4. The school staff's self-assessed capability to manage TDIs if they occurred was not optimistic, as the majority (61\%) of the participants answered that they would not be capable. Consequently, more than two-thirds $(76.2 \%)$ reported that learning about TDIs is very important, and the majority were willing to receive further information about TDIs (81.6\%).

Table 3 Responses to part III: case scenarios

\begin{tabular}{|c|c|}
\hline Questions & Total N=2,027, n (\%) \\
\hline \multicolumn{2}{|l|}{ Case I: an II-year-old child fell and broke an upper front tooth (Figure I) } \\
\hline \multicolumn{2}{|l|}{ QI. Should the broken piece of the tooth be saved? } \\
\hline a. Yes & $669(33.0)$ \\
\hline b. No & $983(48.5)^{*}$ \\
\hline c. I do not know & $375(18.5)$ \\
\hline \multicolumn{2}{|l|}{ Q2. The immediate action should be: } \\
\hline a. Send the child immediately to the dentist & $1,749(86.3)^{* *}$ \\
\hline b. Let the child rest & $126(6.2)$ \\
\hline c. I do not know & $152(7.5)$ \\
\hline \multicolumn{2}{|l|}{ Case II: a 9-year-old child fell down and the upper front tooth was knocked out (Figure 2) } \\
\hline \multicolumn{2}{|l|}{ QI. What will be your immediate action? } \\
\hline a. Replant the tooth and send the child to the dentist immediately & $164(8.1)$ \\
\hline b. Save the tooth in a storage medium and send the child to the dentist immediately & $850(41.9)^{*}$ \\
\hline c. Stop the bleeding and let the child rest & $709(35.0)$ \\
\hline d. Not sure what to do & $304(15.0)$ \\
\hline \multicolumn{2}{|l|}{ Q2. The knocked-out tooth is likely to be: } \\
\hline a. A baby tooth & $837(41.3)^{*}$ \\
\hline b. A permanent tooth & $683(33.7)$ \\
\hline c. I do not know & $507(25.0)$ \\
\hline \multicolumn{2}{|l|}{ Q3. Which storage medium is suitable for storing the knocked-out tooth? } \\
\hline a. Tap water & $371(18.3)$ \\
\hline b. Antiseptic solution & $164(8.1)$ \\
\hline c. Tissue paper & $213(10.5)$ \\
\hline d. Milk & $448(22.1)$ \\
\hline e. Normal saline & $83 I(4 I .0)^{* *}$ \\
\hline
\end{tabular}

Note: $* P<0.05 ; * * P<0.01$, resulting from $\chi^{2}$ test. 


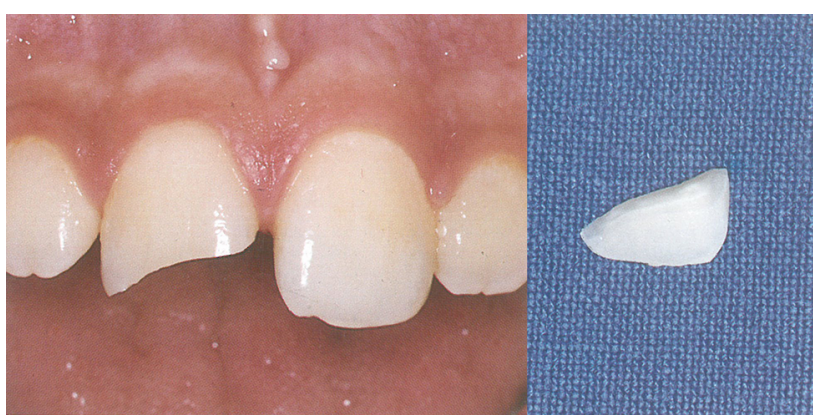

Figure I Crown fracture of maxillary right permanent central incisor.

Note: Adapted with permission from Andreasen JO, Andreasen FM. Essentials of Traumatic Injuries to the Teeth: A Step-by-Step Treatment Guide. Hoboken, NJ: John Wiley \& Sons; 2010. Copyright (C) 2000 J.O. Andreasen, F.M. Andreasen and Munksgaard. ${ }^{15}$

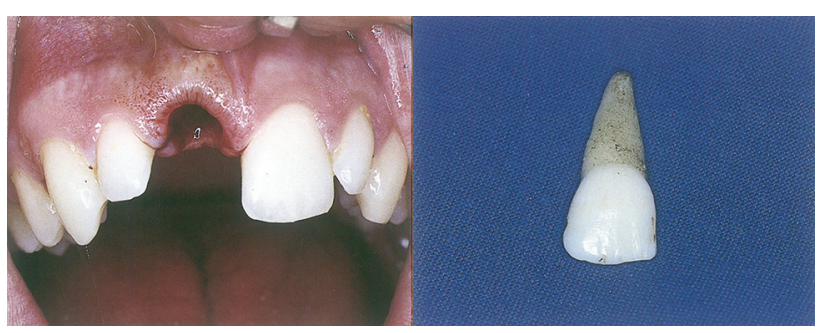

Figure 2 Avulsion of maxillary right permanent central incisor.

Note: Adapted with permission from Andreasen JO, Andreasen FM. Essentials of Traumatic Injuries to the Teeth: A Step-by-Step Treatment Guide. Hoboken, NJ: John Wiley \& Sons; 2010 . Copyright (C) 2000 J.O. Andreasen, F.M. Andreasen and Munksgaard. ${ }^{15}$

Table 4 Responses to part IV: responses to questions regarding management of TDls and further education

\begin{tabular}{|c|c|}
\hline Questions & $\begin{array}{l}\text { Total } N=2,027 \\
\text { n (\%) }\end{array}$ \\
\hline \multicolumn{2}{|c|}{ QI. Are you capable of managing TDls if they } \\
\hline \multicolumn{2}{|c|}{ happen? } \\
\hline a. Yes & $791(39.0)$ \\
\hline b. No & $\mathrm{I}, 236(61.0)$ \\
\hline \multicolumn{2}{|c|}{ Q2. How important is learning about TDIs? } \\
\hline a. Very important & $\mathrm{I}, 545(76.2)$ \\
\hline b. Important & $458(22.6)$ \\
\hline c. Not important & $24(1.2)$ \\
\hline \multicolumn{2}{|c|}{ Q3. Would you like to receive information about } \\
\hline \multicolumn{2}{|c|}{ TDls? } \\
\hline a. Yes & $1,654(81.6)$ \\
\hline b. No & $373(18.4)$ \\
\hline
\end{tabular}

Note: Descriptive statistics showing number and percentage.

Abbreviation: TDls, traumatic dental injuries.

\section{Discussion}

This study included various staff members from randomly selected government and private elementary schools in Riyadh City, Saudi Arabia. Children spend more time at school than at any other location outside the home; while they are there, they involve themselves in various physical activities that expose them to the risk of TDIs. ${ }^{16}$ Thus, the school environment is a suitable place to promote oral healthrelated campaigns targeting the welfare of children. School staff are the most likely people to connect with children soon after a traumatic incident, and it is their knowledge and understanding of emergency procedures that ensure the best prognosis for the clinical treatment provided by the dentist. Consequently, school staff are key strategic vectors for imparting knowledge and awareness of serious healthrelated issues, such as TDIs. ${ }^{17}$

The present study revealed that most of the school staff had neither attended any TDIs training courses $(81.9 \%)$ nor received any information about TDIs in the past (61.4\%). Similar findings indicating a lack of training or information about TDIs were also reported by school teachers in other countries. ${ }^{5,17,18}$

Part III of the questionnaire presented 2 case scenarios likely to be encountered at school followed by simple, concise, closed-ended questions. Most of the relevant studies in the dental literature have found that irrespective of nationality, school teachers' knowledge of TDIs and their management was inadequate ${ }^{5,8,9,12,14,19}$ unless certain intervention measures were undertaken or the staff were deliberately given specific dental trauma-based first-aid training. ${ }^{20}$ Possible reasons this lack of knowledge among school teachers may be that TDIs and their management are not given importance in teacher training and continuing education and that teachers lack exposure to dental trauma management at school as such incidents may be managed by school nurses. ${ }^{14}$

In the first case scenario, in which an 11-year-old child had fallen and broken a maxillary permanent central incisor, the respondents were not aware of the importance of saving the broken piece of tooth, but the majority were aware of the urgency of the situation. There are 2 main reasons the broken piece of tooth needs to be saved and taken to the dentist with minimal delay. The first and most important reason is to ensure that the child has not aspirated the tooth fragment, which otherwise would require a chest radiograph to ascertain. Second, it may be possible to bond the tooth fragment back to the remaining tooth, although this is not an option in all cases.

The second case scenario pertained to the management of an avulsed maxillary permanent central incisor in a 9-yearold child. The basic knowledge that a 9-year-old child has permanent upper front teeth was correctly answered by only $33.7 \%$ of the respondents; this response is consistent with similar studies conducted in the United Arab Emirates. ${ }^{11,12}$ In contrast, Indian school teachers were confidently able to distinguish between primary and permanent dentition. ${ }^{5,21} \mathrm{~A}$ lack of knowledge about tooth identification suggests that 
school staff members may take actions that could have future adverse consequences. In the present study, the option of replanting the tooth was selected by only $8.1 \%$ of the school staff. It is vital for school staff to be aware that an avulsed primary tooth should not be reimplanted to avoid/minimize damage to its permanent successor; however, an avulsed permanent tooth should be immediately reimplanted to maintain periodontal cell viability. ${ }^{22}$

A study regarding knowledge about tooth avulsion and its management among dental assistants in Riyadh reported that milk was the most suitable storage medium. ${ }^{23}$ This is inconsistent with a study conducted among school nurses, $82 \%$ of whom reported that saline was the recommended storage medium. ${ }^{24}$ Although intrinsic factors of each individual may affect the prognosis of the cases affected by TDIs, certain storage media are indicated in circumstances where the time period since the incidence of the trauma has been long, such as Hank's balanced salt solution or the tooth rescue box, the latter contains a culture medium comprising amino acids, vitamins, and glucose. ${ }^{25}$ However, among the storage media readily available at the time of the occurrence of TDIs such as milk, water, saliva or saline, pasteurized milk has been considered the most favorable. ${ }^{26}$

In this study, certain limitations merit mention in order to improve on future studies. Being a questionnaire-based survey, there might be underreported elements in the study. The cross-sectional study design and nonrespondent bias may be considered as another drawback.

The results of this study may help in making strategic plans to enhance the elementary school staffs' knowledge about TDIs and the long-term consequences following TDIs incident. For instance, educational programs in the form of workshops and seminars with appropriate decision-making in the management of TDIs may be initiated as part of school staffs' professional development.

\section{Conclusion}

A lack of knowledge regarding certain aspects of TDIs management in children was evident among elementary school staff. Therefore, health education programs in the form of seminars or training workshops focusing on TDIs delivered to school staff on a regular basis may provide greater insight into how to most efficiently manage TDIs.

\section{Acknowledgment}

The authors thank College of Dentistry Research Center and Deanship of Scientific Research at King Saud University, Saudi Arabia, for funding this study.

\section{Disclosure}

The authors report no conflicts of interest in this work.

\section{References}

1. Diangelis AJ, Andreasen JO, Ebeleseder KA, et al. International Association of Dental Traumatology guidelines for the management of traumatic dental injuries: 1. Fractures and luxations of permanent teeth. Dent Traumatol. 2012;28(1):2-12.

2. Glendor U. Epidemiology of traumatic dental injuries - a 12 year review of the literature. Dent Traumatol. 2008;24(6):603-611.

3. Lee JY, Divaris K. Hidden consequences of dental trauma: the social and psychological effects. Pediatr Dent. 2009;31(2):96-101.

4. Chan AW, Wong TK, Cheung GS. Lay knowledge of physical education teachers about the emergency management of dental trauma in Hong Kong. Dent Traumatol. 2001;17(2):77-85.

5. Nirwan M, Syed AA, Chaturvedi S, Goenka P, Sharma S. Awareness in primary school teachers regarding traumatic dental injuries in children and their emergency management: a survey in South Jaipur. Int J Clin Pediatr Dent. 2016;9(1):62-66.

6. Andreasen JO, Borum MK, Jacobsen HL, Andreasen FM. Replantation of 400 avulsed permanent incisors. 4. Factors related to periodontal ligament healing. Endod Dent Traumatol. 1995;11(2):76-89.

7. Bendo CB, Paiva SM, Varni JW, Vale MP. Oral health-related quality of life and traumatic dental injuries in Brazilian adolescents. Community Dent Oral Epidemiol. 2014;42(3):216-223.

8. Marcano-Caldera M, Mejía-Cardona JL, Parra Sanchez JH, et al. Knowledge about emergency dental trauma management among school teachers in Colombia: a baseline study to develop an education strategy. Dent Traumatol. 2018;34(3):164-174.

9. Skeie MS, Audestad E, Bårdsen A. Traumatic dental injuries knowledge and awareness among present and prospective teachers in selected urban and rural areas of Norway. Dental Traumatology. 2010;26(3):243-247.

10. Addo ME, Parekh S, Moles DR, Roberts GJ. Knowledge of dental trauma first aid (DTFA): the example of avulsed incisors in casualty departments and schools in London. Br Dent J. 2007;202(10):E27.

11. Awad MA, Alhammadi E, Malalla M, et al. Assessment of elementary school teachers' level of knowledge and attitude regarding traumatic dental injuries in the United Arab Emirates. Int $J$ Dent. 2017;20(7):1-7.

12. Hashim R. Dental trauma management awareness among primary school teachers in the Emirate of Ajman, United Arab Emirates. Eur J Paediatr Dent. 2011;12(2):99-102.

13. Quaranta A, de Giglio O, Trerotoli P, et al. Knowledge, attitudes, and behavior concerning dental trauma among parents of children attending primary school. Ann Ig. 2016;28(6):450-459.

14. Feldens EG, Feldens CA, Kramer PF, da Silva KG, Munari CC, Brei VA. Understanding school teacher's knowledge regarding dental trauma: a basis for future interventions. Dent Traumatol. 2010;26(2):158-163.

15. Andreasen JO, Andreasen FM. Essentials of Traumatic Injuries to the Teeth: A Step-by-Step Treatment Guide. Hoboken, NJ: John Wiley \& Sons; 2010.

16. Faus-Damiá M, Alegre-Domingo T, Faus-Matoses I, Faus-Matoses V, Faus-Llácer VJ. Traumatic dental injuries among schoolchildren in Valencia, Spain. Med Oral Patol Oral Cir Bucal. 2011;16(2): e292-e295.

17. Antunes LA, Rodrigues AS, Martins AM, Cardoso ES, Homsi N, Antunes LS. Traumatic dental injury in permanent teeth: knowledge and management in a group of Brazilian school teachers. Dent Traumatol. 2016;32(4):269-273.

18. Nemutandani MS, Yengopal V, Rudolph MJ. Teachers' knowledge of emergency management of traumatised teeth in preschools. SADJ. 2011;66(1):26-29.

19. Al-Jundi SH, Al-Waeili H, Khairalah K. Knowledge and attitude of Jordanian school health teachers with regards to emergency management of dental trauma. Dent Traumatol. 2005;21(4):183-187. 
20. Taranath M, Senaikarasi RM, Manchanda K. Assessment of knowledge and attitude before and after a health education program in East Madurai primary school teachers with regard to emergency management of avulsed teeth. J Indian Soc Pedod Prev Dent. 2017;35(1):63-67.

21. Bhandary S, Shetty S. Knowledge of physical education teachers regarding dental trauma and its management in Karnataka. Int J Res Dent. 2014;4(1):20-31.

22. Wilson CF. Management of trauma to primary and developing teeth. Dent Clin North Am. 1995;39(1):133-167.

23. Halawany HS, Aljazairy YH, Alhussainan NS, Almaflehi N, Jacob V, Abraham NB. Knowledge about tooth avulsion and its management among dental assistants in Riyadh, Saudi Arabia. BMC Oral Health. 2014;14(1):46.
24. Baginska J, Wilczynska-Borawska M. Knowledge of nurses working at schools in Bialystok, Poland, of tooth avulsion and its management. Dent Traumatol. 2012;28(4):314-319.

25. Brunet-Llobet L, Lahor-Soler E, Miranda-Rius J. Replantation of an avulsed tooth after one day of storage in adverse extraoral dry conditions: acceptable outcome after a 10-year follow-up. Quintessence Int. 2018;49(1):25-31

26. de Souza BD, Bortoluzzi EA, Reyes-Carmona J, Reyes C, et al. Effect of temperature and seven storage media on human periodontal ligament fibroblast viability. Dent Traumatol. 2017;33(2):100-105.
Clinical, Cosmetic and Investigational Dentistry

\section{Publish your work in this journal}

Clinical, Cosmetic and Investigational Dentistry is an international, peer-reviewed, open access, online journal focusing on the latest clinical and experimental research in dentistry with specific emphasis on cosmetic interventions. Innovative developments in dental materials, techniques and devices that improve outcomes and patient satisfac-
Dovepress

tion and preference will be highlighted. The manuscript management system is completely online and includes a very quick and fair peerreview system, which is all easy to use. Visit http://www.dovepress. com/testimonials.php to read real quotes from published authors.

Submit your manuscript here: https://www.dovepress.com/clinical-cosmetic-and-investigational-dentistry-journal 